\title{
Üst gastrointestinal sistem endoskopi uygulanan hastalarda intestinal metaplazi sıklığının araştırılması
}

\author{
Investigation of the incidence of metaplasia in patients undergoing upper gastrointestinal system \\ endoscopy
}

(D) Muhammet Fatih AYDIN

Altınbaş Üniversitesi, Bahçelievler Medikal Park Hastanesi Gastroenteroloji Kliniği, İstanbul

\begin{abstract}
Giriş ve Amaç: Intestinal metaplazi; epitelyumun, kronik mukozal irritasyona bağlı olarak bağırsakta bulunana benzer bir epitel türüne dönüşümüdür. Intestinal metaplazinin risk faktörleri; Helicobacter pylori enfeksiyonu, etnik köken, sigara ve alkol kullanımı, hormonlar, pH'daki değişimler, yüksek tuz alımı ve kronik safra reflüsünü içermektedir. Bu çalısmanın amacı, farklı endikasyonlarla endoskopi uygulanan hastalarda intestinal metaplazi varlığını ve risk faktörleri ile ilişkisini araştırmak, ayrıca literatür eşliğinde intestinal metaplazi yaygınlığını irdelemektir. Gereç ve Yöntem: Hastaların yaş ve cinsiyet gibi demografik özellikleri, sigara ve alkol kullanımı, aile öyküsü, pilorun açıkık durumu, endoskopik metaplazi bulguları, patolojik bulguları (histopatolojik özellikler, safra gastriti, Helicobacter pylori, atrofi, displazi ve intestinal metaplazi varlığı) intestinal metaplazi türü, Helicobacter pylori varlığı, kaydedilerek retrospektif olarak analiz edilmiştir. Bulgular: Çalışmaya yaşları 15-49 yıl arasında değişmekte olan toplam 217 hasta dahil edilmiştir. Hastaların 106'sı (\%48.8) erkek olup, ortalama yaş 33.23 7.87 yıl olarak saptanmıştır. Katılımcıların 88'i (\%43.3) sigara ve 46'sı (\%22.7) alkol kullanmaktadır. Hastaların 51'inde (\%23.5) endoskopide metaplazi görüntüsü saptanırken, patolojik raporu metaplazi olarak gelen hastaların sayısı ise 72 'dir (\%33.18). Saptanan metaplazilerin tamamı komplet tür metaplazidir. Hastaların 85'inde (\%39.17) Helicobacter pylori pozitif saptanırken, bu hastaların 75'inde (\%34.56) Helicobacter pylori varlığı patolojik olarak doğrulanmıştır. Metaplazi saptanan ve saptanmayan olgular arasında Helicobacter pylori pozitifliği, sigara ve alkol kullanımı, yaş, cinsiyet ve aile öyküsü açısından anlamlı fark saptanmamıştır (hepsi için $p$ >0.05). Sonuç: Intestinal metaplazi sıklığı yeme alışkanlıkları ve yaşam tarzı değişiklikleri ile büyük ölçüde azaltılabilir. Intestinal metaplazinin yeterince erken bir aşamada saptanarak tedavi edilmesi, mide kanseri sıkı̆̆ının azaltılması açııından büyük önem taşımaktadır.
\end{abstract}

Anahtar kelimeler: intestinal metaplazi, Helicobacter pylori, endoskopi, patoloji, gastrik kanser

\section{GíRiş}

Metaplazi, farklılaşan bir hücre türünün normal olarak spesifik bir dokuda bulunan diğer bir farklılaşmış olgun hücre türü ile yer değiştirmesi olarak tanımlanmaktadır (1). Metaplazi asit veya bazik irritasyona bağlı oluşabilen (pH bağımlı), hormonlar, sigara kullanımı ve alkol gibi uyaranlar tarafından indüklenebilmekte veya hızlandırılabilmektedir (2). Anormal uyaranlar bağlamında orijinal

Iletişim: Muhammed Fatih AYDIN

Altınbaş Üniversitesi, Bahçelievler Medikal Park Hastanesi Gastroenteroloji Kliniği, İstanbul

Tel: +90 2124841484 • E-mail: drmfatih@hotmail.com
Background and aims: Intestinal metaplasia is the transformation of the epithelium such that it resembles the epithelium of intestines with chronic mucosal irritation. Risk factors of intestinal metaplasia include Helicobacter pylori infection, ethnic origin, smoking and alcohol consumption, hormones, changes in $\mathrm{pH}$, high salt intake, and chronic biliary reflux. The objective of this study was to investigate the presence of intestinal metaplasia and its relationships with the risk factors in those patients who underwent endoscopy with different indications and to examine whether the incidence of intestinal metaplasia agreed with the facts reported in the literature. Materials and methods: Patients' demographic features, such as age and gender, smoking and alcohol consumption, and family history were recorded and retrospectively analyzed. In addition, the patency status of the pylorus, endoscopic metaplasia findings, pathologic findings (histopathologic features, biliary gastritis, Helicobacter pylori, atrophia, dysplasia, and intestinal metaplasia), type of intestinal metaplasia, and the presence of Helicobacter pylori were recorded and retrospectively analyzed. Results: A total of 217 patients aged between 15 and 49 years were included in the study. Of all patients, 106 (48.8\%) were males, and the mean age was found as $33.23 \pm 7.87$ years. Eighty-eight $(43.3 \%)$ of the participants were smokers, and 46 (22.7\%) used alcohol. Metaplasia was detected with endoscopy in 51 (23.5\%) patients, while the pathology report indicated metaplasia in 72 (33.18\%) patients. All metaplasia detected were of the complete type. Helicobacter pylori was positive in 85 (39.17\%) patients, while the presence of Helicobacter pylori was pathologically confirmed in 75 (34.56\%) of these patients. No significant difference was observed in between patients with and without metaplasia regarding Helicobacter pylori positivity, smoking and alcohol, age, gender, and family history ( $p>0.05$ for all). Conclusion: The incidence of intestinal metaplasia can be largely reduced by improving eating habits and making lifestyle changes. Early detection and treatment of intestinal metaplasia is of paramount importance for reducing the incidence of gastric cancer.

Keywords: Intestinal metaplasia, Helicobacter pylori, endoscopy, pathology, gastric cancer

hücreler kimlik değiştirerek çevresel strese adapte olur. Metaplaziye neden olan uyaran ortadan kaldıııldı̆ında dokuların kendi normal farklılaşma paternlerine geri dönüp dönmeyeceği tam olarak açık değildir. Ancak metaplaziyi kolaylaştıran zararlı uyaranların sürekli varlığı halinde ise, metaplazi displaziye ve sonunda maligniteye doğru yol almaktadır $(3,4)$.

Aydın MF. Investigation of the incidence of metaplasia in patients undergoing upper gastrointestinal system endoscopy. The Turkish Journal of Academic Gastroenterology 2020;19:11-16. DOI: 10.17941/agd.729407

Geliş Tarihi: 09.12.2019 • Kabul Tarihi: 24.04.2020 
Metaplazi daha çok sürekli olarak çevresel etkenlere maruz kalan dokularda oluşma eğilimindedir. Örneğin pulmoner sistem ile gastrointestinal kanal, sırasiyla hava ve besinlerle temasları nedeniyle yaygın metaplazi alanlarıdır (5).

Metaplazi türü, bulunduğu dokuya bağııdır. Geniş anlamda metaplazi üç türe ayrılabilir: Skuamöz metaplazi, asinar-duktal metaplazi ve intestinal metaplazi. Skuamöz metaplazi, endometrium kolumnar yüzey ve bez epitelinin stratifiye skuamöz epitelle yer değiştirmesi olarak tanımlanabilir (6). Skuamöz metaplazinin en yaygın alanları mesane ve servikstir. Asinar-duktal metaplazinin pankreatik pre-neoplastik lezyonların ana kaynağı olduğu düşünülmektedir (7).

Intestinal metaplazi (IM) ise diğer türlere göre çok daha yaygın olup, araştırmalara daha sık konu olmuştur. iM epitelyumun genellikle mide veya özofagusta kronik mukozal irritasyona bağlı olarak bağırsakta bulunan epitele benzer bir epitel türüne dönüşümüdür. Goblet hücreleri görünümü ve transkripsiyon faktörü CDX2 gibi intestinal hücre belirteçlerinin ekspresyonuyla karakterizedir (8). iM'nin etiyopatogenezinde; Helicobacter pylori (H. pylori), etnik köken, sigara ve alkol kullanımı, hormonlar, pH değişimleri, yüksek miktarda tuz alımı ve kronik safra reflüsü gibi faktörler rol oynamaktadır. Illave risk faktörleri ise ileri yaş, belirli etnik kökenler ve erkek cinsiyeti içermektedir (9). IM komplet (tip I) ve inkomplet (tip II ve tip III) olmak üzere ikiye ayrımaktadır. Komplet intestinal metaplazi ince barsak epiteline benzerken, inkomplet intestinal metaplazi ise kolonik epitele benzemektedir (10).

IM endoskopide yaygın bir bulgu olarak karşımıza çıkmaktadır. Gastrik karsinogenezde erken bir aşama olduğu belirlenmiş olup, özellikle inkomplet kolonik IM'nin (tip III) yüksek riskli popülasyonlarda (örn. Asya ülkeleri) önemli oranda neoplaziye ilerlediği gösterilmiştir (11). Çalışmalar, IM bulunan her 860 kişiden 1'inin (\%0.12) kansere ilerlediğini bildirmektedir (12). Hijyen ve diğer ekzojen riskler nedeniyle sosyoekonomik düzeyi nispeten düşük toplumlarda IM sıklığı artmaktadır. IM prevalansı ülkeden ülkeye önemli oranda değişiklik göstermektedir. Peleterio ve ark. tarafından IM'nin insidansını araştıran çeşitli çalışmalardan yapılan bir derlemede iM prevalansı Mısır'da \%24.4, Arjantin'de \%1.8, Çin'de \%33, Hindistan'da \%6.5, İtalya'da \%20.2, İsveç'te \%7.1 olarak bildirilirken, Türkiye'de ise bu prevalansın \%48.1 olduğu belirtilmiştir (Peleterio).

Bu çalışmamızın amacı, çeşitli endikasyonlarla endoskopi uygulanan hastalarda IM varlığını ve risk faktörleri ile ilişkisini araştırmak, ayrıca literatür eşliğinde tek merkez verileri üzerinden IM yaygınlığını irdelemektir.

\section{GEREÇ ve YÖNTEM}

Bu çalışmada 01.01.2018 ile 30.06.2018 tarihleri arasında çeşitli endikasyonlarla hastanemizin gastroenteroloji polikliniğine gastrointestinal şikayetlerle başvuran ve üst gastrointestinal sistem endoskopisi uygulanan 15-49 yaş arası 300 hastada, intestinal metaplazi varlığı ve özellikleri, hastane kayıt sistemi taranarak elde edilen verilerle retrospektif olarak değerlendirilmiştir. Gastrik cerrahi geçiren hastalar, üst gastrointestinal sistem kanaması olanlar, malignite öyküsü olanlar, 18 yaş altında olan ve verileri eksik olan 83 hasta çalışma dışı bırakıldıktan sonra geriye kalan 217 hasta çalışmaya dahil edilmiştir.

Hastaların yaş ve cinsiyet gibi demografik özellikleri, sigara ve alkol kullanımı, aile öyküsü, pilorun açıklık durumu, endoskopik metaplazi bulguları, (endoskopi ışığında gözle seçilebilen, metaplazik olduğu şüphelenilen alanlar), patolojik bulguları (histopatolojik özellikler, safra gastriti, H. pylori varlı̆ı̆, atrofi, displazi ve intestinal metaplazi varlığı, intestinal metaplazi türü), kaydedilerek retrospektif olarak analiz edilmiştir. Endoskopi endikasyonları; abdominal ağrı, anemi, dispeptik yakınmalar, gastroözofageal reflü, ailede mide kanser öyküsü olması ve izlem amaçlı yapılan işlemleri içermiştir. Endoskopi ünitesinde hastalar en az 8 saatlik açlı̆ı takiben sedo-analjezi altında tüm üst gastrointestinal sistem mukozası incelenmiştir. Her hastadan minimal 3 adet biyopsi örneklemesi yapılmıştır. Ülser ve malignite kuşkulu lezyondan ekstra olarak bu lezyonlara yönelik tanımlayıcı miktarda örnekler alınmıştır.

\section{Histolojik Değerlendirme}

Hastaların tümünden patolojik inceleme amacıyla alınan biyopsi örnekleri \%10'luk formalin solüsyonuna fikse edilmiş, patoloji laboratuvarında parafin bloklara gömülmüş, 0.4 um kalınlığında kesitler alınmış ve Hematoksilin/ Eozin ile boyanarak analiz edilmiştir. Patolojik olarak IM tanısı boyanan kesitlerde normalde mide mukozasında görülmeyen, ancak bağırsak epitelinde görülebilen, goblet, absortif, Paneth ve endokrin hücrelerin varlığı ile konulmuştur (10). Histopatolojik bulgulara göre intestinal metaplaziler komplet ve inkomplet olmak üzere iki gruba ayrılmışır.

\section{Heliobacter pylori Enfeksiyonunun Saptanması}

$H$. pylori'ye özgü immünoglobulinler (Ig) $\mathrm{G}$ ve $\lg A$ tüm serum numunelerinde Enzim Bağlı İmmün Assay (ELISA) ile ölçülmüştür. H. pylori varlığı ayrıca immünohistokimyasal testlerle de doğrulanmıştır. 


\section{Etik Onay}

Çalışma protokolü hastanemizin yerel etik kurulu tarafından onaylanmıştır. Çalışma Helsinki Deklarasyonu ilkeleri doğrultusunda yürütülmüştür.

\section{İstatistiksel Analiz}

Çalışmada elde edilen veriler IBM SPSS versiyon 22.0 (IBM, SPSS, Chicago, IL, ABD) paket programı ile analiz edilmiştir. Parametrelerin normal dağılıma uygunluğu Shapiro Wilks testi ile değerlendirilmiştir. Çalışma verileri değerlendirilirken, tanımlayıcı istatistiksel yöntemlerin (ortalama, standart sapma, sayı, yüzde) yanı sıra niceliksel verilerde normal dağıım gösteren parametrelerin iki grup arasında karşılaşıtııımasında Student t testi kullanılmıştır. Niteliksel verilerin karşılaştııılmasında ise Ki kare testi, Fisher Exact testi ve Continuity (Yates) düzeltmesi kullanılmıştır. İstatistiksel anlamlılık $p<0.05$ düzeyinde değerlendirilmiştir.

\section{BULGULAR}

Bu çalışmada. Hastaların 106'sı (\%48.8) erkek ve $111^{\prime} \mathrm{i}$ (\%51.2) kadındır. Hastaların yaş ortalaması 33.23 \pm 7.87 yıl olarak saptanmıştır. Olguların 203'ünün sigara ve alkol kullanım bilgisine ulaşılmıştır. Buna göre tüm katılımcıların $88^{\prime} \mathrm{i}$ (\%43.3) sigara ve 46'sı (\%22.7) alkol kullanmaktadır. Toplam 6 (\%2.76) hastada aile öyküsü saptanmıştır. Hastaların pilor açıkığı değerlendirildiğinde; 46 (\%21.20) hastada pilor normal, 171 (\%78.80) hastada açık olduğu saptanmıştır.

Endoskopik incelemede hastaların 51'inde (\%23.5) metaplazi görüntüsü saptanırken, patolojik raporu metaplazi olarak gelen hastaların sayısı ise 72 (\%33.18) idi (Şekil 1, 2).

Endoskopik incelemede metaplazi görüntüsü saptanan hastaların ortalama yaşı $36.55 \pm 9.18$ yıl olarak saptanırken, patolojik olarak metaplazi saptanan hastaların ortalama yaşı ise $34.53 \pm 8.01$ yll olarak bulunmuştur. Endoskopik ve patolojik incelemelerde metaplazi saptanan hastaların ortalama yaşları arasında istatistiksel olarak anlamlı fark yoktur $(p>0.05)$. Ayrıca patolojik metaplazi erkek hastaların 31'inde (\%29.25) ve kadın hastaların 41 'inde (\%36.94) saptanmıştır. Her iki cinsiyet arasında patolojik metaplazi sıklığı açısından istatistiksel olarak anlamlı fark mevcut değildir $(p>0.05)$. Histopatolojik incelemede saptanan metaplazilerin türleri incelendiğinde hiçbir hastada inkomplet metaplazi saptanmaz iken, 72 (\%33.18) hastada ise komplet metaplazi saptanmıştır. Ayrıca 66 (\%30.41) hastada patolojik olarak atrofi saptanmıştır.
Hastaların 136'sında (\%62.67) endoskopik safra gastriti mevcut idi. Hastalar H. pylori varlığı açısından değerlendirildiğinde; hastaların $85^{\prime}$ inde (\%39.17) H. pylori pozitif saptanırken, bu hastaların 75'inde (\%34.56) H. pylori varı̆̆ı patolojik olarak doğrulanmıştır (Şekil 3).

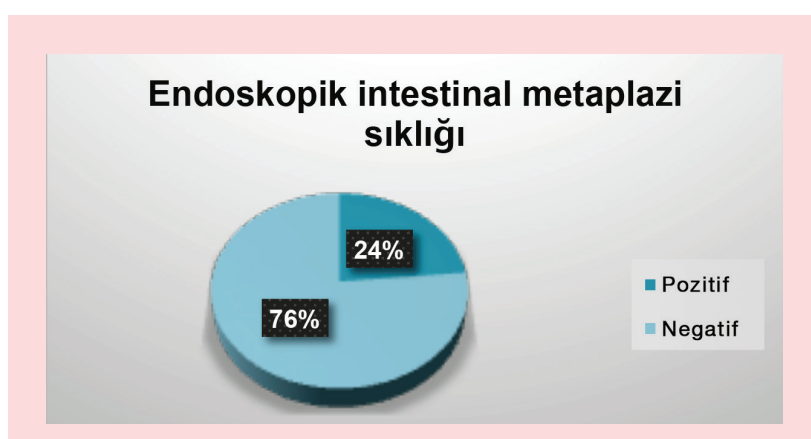

Şekil 1. Endoskopide intestinal metaplazi görüntüsü.

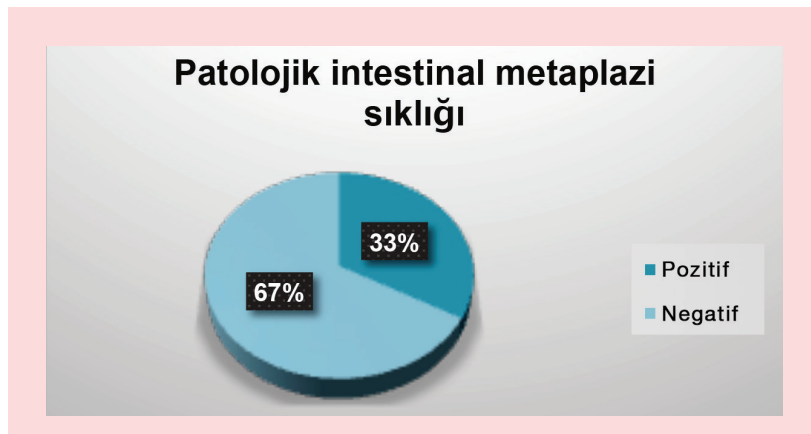

Şekil 2. Patolojik intestinal metaplazi sıklığı.

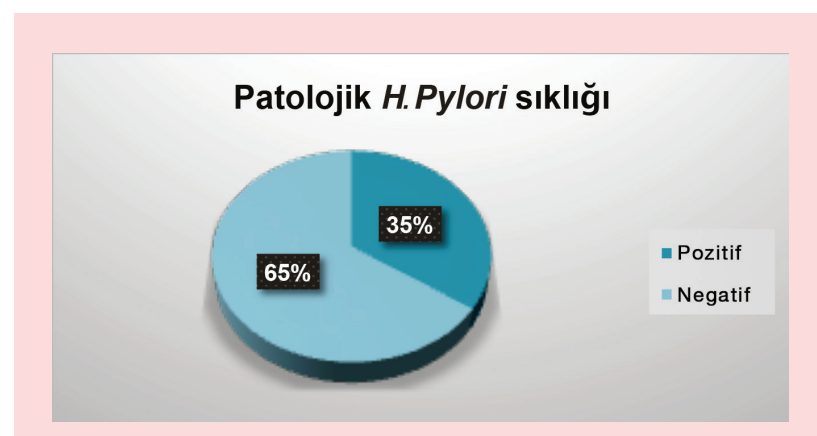

Şekil 3. Patolojik incelemede doğrulanan H. pylori sıklığı.

Safra gastriti bulunan hastaların 43'ünde patolojik metaplazi saptanırken, safra gastriti bulunmayanlardan yalnızca 1 hastada metaplazi saptanmıştır. Buna göre safra gastriti bulunan ve bulunmayan olgular arasında patolojik metaplazi varlığı açısından istatistiksel olarak anlamlı farklılık saptanmamışıı $(p>0.05)$. 
Tablo 1. Hasta grupta H. pylori +safra gastrit sıklığına göre patolojik metaplazi ve patolojik atrofi sıklığının değerlendirilmesi

\begin{tabular}{|c|c|c|c|}
\hline \multicolumn{4}{|c|}{ Safra Gastriti+ H. pylori Sıklığı } \\
\hline & Pozitif n (\%) & Negatif $\mathrm{n}(\%)$ & p \\
\hline \multicolumn{4}{|c|}{ Patolojik metaplazi } \\
\hline Pozitif & $43(\% 32.3)$ & $1(\% 100)$ & 0.328 \\
\hline Negatif & $90(\% 67.7)$ & $0(\% 0)$ & \\
\hline \multicolumn{4}{|c|}{ Patolojik atrofi } \\
\hline Pozitif & $41(\% 30.8)$ & $0(\% 0)$ & 1.000 \\
\hline Negatif & $92(\% 69.2)$ & $1(\% 100)$ & \\
\hline
\end{tabular}

Fisher's Exact test

Tablo 2. Patolojkk metaplazi pozitifliğine göre komplet metaplazi ve inkomplet metaplazi değerlendirilmesi

\begin{tabular}{|c|c|c|c|}
\hline \multicolumn{4}{|c|}{ Safra Gastriti+ H. pylori Sıklığı } \\
\hline Grup & Pozitif n (\%) & Negatif n (\%) & $\mathbf{p}$ \\
\hline \multicolumn{4}{|l|}{ Komplet metaplazi } \\
\hline Pozitif & $44(\% 100)$ & $0(\% 0)$ & 0.001 * \\
\hline Negatif & $0(\% 0)$ & $90(\% 100)$ & \\
\hline \multicolumn{4}{|l|}{ İnkomplet atrofi } \\
\hline Pozitif & - & - & - \\
\hline Negatif & $44(\% 100)$ & $90(\% 100)$ & \\
\hline
\end{tabular}

H. pylori pozitif olguların \%30.8'inde ve $H$. pylori negatif olguların \%34.1'inde patolojik metaplazi saptanmış olup, aralarındaki fark istatistiksel olarak anlamlı değildir ( $p>0.05)$. Hastaların H. pylori+safra gastriti sıklığına göre patolojik metaplazi ve atrofi sıklığı Tablo 1'de görülmektedir.

Patolojik metaplazi bulunan ve bulunmayan hastaların yaş ortalamaları arasında istatistiksel olarak anlamlı fark mevcut değildir ( $p>0.05$ ). Sigara kullanan ve kullanmayan hastalar arasında patolojik metaplazi ve $H$. pylori sıklığı açısından anlamlı fark yoktur (hepsi için: $p>0.05$ ). Alkol kullanan ve kullanmayan hastalar arasında patolojik metaplazi ve $H$. pylori sıklığı açısından anlamlı fark yoktur (hepsi için: $p$ >0.05). Aile öyküsü olan ve olmayan hastalar arasında patolojik metaplazi sıklığı açısından anlamlı fark yoktur ( $p>0.05)$.

Patolojik metaplazi pozitifliğine göre komplet ve inkomplet metaplazi dağılımı Tablo 2'de verilmektedir.

\section{TARTIŞMA}

Intestinal metaplazinin (IM) gastrik kansere yol açabilen prekanseröz bir lezyon olduğu düşünülmektedir. İM bulunan hastalarda gastrik kanser gelişme riskinin altı kat arttığı bildirilmiştir (13). Bazı çalışmalarda IM bulunan hastaların endoskopik-histolojik takibi ile gastrik kanserin erken bir aşamada saptanarak mortalite oranının önemli derecede azaltılabileceği bildirilmiştir (14). Ancak IM bulunan hastaların endoskopik takibi ile ilgili bir kılavuz bulunmadığından, IM hastalarında gözetim stratejisinin klinik olarak benimsenmesi konusu belirsizliğini korumaktadır.

iM bulunan 61707 hastalık bir kohortta 874 hastada 10 yıllık bir sürede gastrik kanser gelişmiş olup, bu sonuç \%1.8'lik bir insidansa karşılık gelmektedir (15). IM yayılımı >\%20, inkomplet tip İM varlığı, aile gastrik kanser öyküsü ve sigara kullanımı risk faktörlerinden en az biri bulunan IM hastalarının yılda bir kez, diğer IM hastalarının ise 2-3 yılda bir kez endoskopik kontrolden geçmesi önerilmiştir (13).

Dünya çapında intestinal metaplazinin yaygınlığı büyük ölçüde bilinmemektedir. Bununla birlikte IM'nin prevalansı ve insidansını bölge bazında bildiren çalışmalar mevcuttur. Sonnenberg ve ark. tarafından yapılan büyük ölçekli retrospektif bir çalışmada $A B D^{\prime}$ de üst endoskopi geçiren 78985 hastada iM prevalansı \%7 olarak saptanmıştır (16). Ancak IM'nin daha çok eksojen etkenlerden kay- 
naklandığı göz önüne alındığında, insidansı etnik kökenler, sosyoekonomik gelişmişlik düzeyi ve coğrafik bölgeler arasında değişkenlik göstermektedir. Hatta aynı ülkede bile farklı bölgeler arasında IM insidansı açısından anlamlı fark görülebilmektedir. Nitekim Türkiye'nin Doğu ve Güneydoğu Anadolu bölgelerindeki gastroenteroloji kliniklerinde IM'nin önemli risk faktörlerinden biri olan H. pylori enfeksiyonu oldukça sık görülmektedir (17). Mete ve ark. tarafından yapılan bir çalışmada ise Tekirdağ bölgesinde hastaların \%13.5'inde metaplazi saptanmıştır (18).

Biz çalışmamızda gastrointestinal şikayetler nedeniyle endoskopik inceleme yapılan hastalarda metaplazinin sıklığını ve risk faktörleri ile ilişkisini inceledik. Bizim çalışmamızda endoskopik inceleme ile IM sıklığı \%23.5 olarak saptanırken, patolojik metaplazi oranı ise \%33.18 olarak bulunmuştur. Geçmiş çalışmalara kıyasla bizim çalışmamızda görülen daha yüksek metaplazi sıklığı, değişen yaşam tarzı ve yeme alıskanlıklarına bağlı olarak IM insidansının giderek arttığını düşündürmektedir. Daha önce belirtildiği gibi iM çok sayıda farklı eksojen etkenlerden kaynaklandığından, farklı bölgelerde yapılan çalışmalar arasında IM insidansı açısından oldukça büyük oranda değişkenlik söz konusudur. Özdil ve ark. tarafından dispeptik yetişkin hastalar üzerinde yapılan bir çalışmada intestinal metaplazi sıklığı \%17.8 olarak saptanmıştır (19). Konakçı ve ark. (20) intestinal metaplazi insidansı \%26.6 olarak bildirirken, bu oran Adım ve ark. (21) tarafından $\% 11.5$, Akpolat ve ark. (22) tarafından \%24, Taşkın ve ark. (23) tarafından yapılan çalışmada ise \%13.7 olarak bildirilmiştir. Yine Ölmez ve ark. tarafından Van bölgesinde yapılan bir çalışmada IM insidansı \%13.8 olarak saptanmıştır (24). Diğer taraftan yurtdışında yapılan çaış̧malar incelendiğinde de yine aynı nedenlerle çalışmalar arasında iM prevalansı açısından farklılıklar mevcuttur. Finlandiya'dan Eriksson ve ark. tarafından yapılan bir çaIışmada IM insidansı \%19 olarak saptanmıştır (25). Campbel ve ark. tarafında Batı Afrika'da yapılan bir çalışmada iM insidansı \%8.9 olarak saptanmıştır (26). Literatürdeki diğer çalışmalarda iM insidansı Kolombiya'da \%38.8 (27), ABD'de \%15 (11), İran'da \%13 (28) ve Avustralya'da \%12.7 (29) olarak bildirilmiştir.

Çalışmamızda hastaların \%34.6'sında patolojik olarak $H$. pylori varlığı saptanmıştır. Benzer şekilde 2019 yılında Güner ve ark. tarafından yapılan bir çalışmada da IM insidansı \%34.67 olarak saptanmıştır (30). Bununla birlikte literatürde $H$. pylori insidansı ile ilgili çalışmalar incelendiğinde ise farklı oranlar bildirildiği görülmektedir. İbiş ve ark. tarafından endoskopik olarak tanımlanan gastrit ve histolojik bulgular arasındaki ilişkinin değerlendirildiği bir çalışmada $H$. pylori insidansı \%71.2 olarak bildirilmiştir (31). Konakçı ve ark. tarafından yapılan çalışmada ise bu oran \%50.5 olarak saptanmıştır (20). Çalışmalar arasında iM ve $H$. pylori insidansı açısından görülen farkların çok çeşitli nedenleri olabilir. Bunlar arasında çalışmaya katılanların endoskopi ve patoloji endikasyonları arasındaki farklar, yaşam tarzı farklılıkları ve çalışmaların yapıldığı bölgeler sayılabilir.

iM'nin risk faktörlerinden biri olan $H$. pylori ile iM insidansları arasındaki ilişki çok sayıda çalışmada araştııımıştır $(17,18,27)$. Yaş ile birlikte IM insidansının arttığı bilinmektedir. Ancak $H$. pylori pozitif olan hastalarda intestinal metaplazinin sıklığı genç yaşlarda artmaktadır. Bizım çalışmamızda hastaların ortalama yaşı 33 yıl olarak saptanmıştır. Güner ve ark. tarafından $H$. pylori pozitif hastalarda IM sıklı̆ının araştııılığı bir çalışmada hastaların ortalama yaşı 47.4 yıl olarak bulunmuştur (30).

Çeşitli çalışmalarda farklı yaşam tarzları ile prekanseröz gastrik lezyonların, özellikle de IM'nin oluşumu arasındaki ilişki ele alınmıştır. Bu yaşam tarzı faktörlerinden en kapsamlı olarak araştırılan ve ì riskini en çok artıran faktör sigaradır (32). Bizim çalışmamızda sigara ve alkol kullanımı ile IM insindası arasında anlamlı bir ilişki saptanmamıştır. Ayrıca aile öyküsü, yaş ortalaması ve cinsiyet ile iM insidansı arasında da anlamlı ilişki saptanmamıştır. Çalışmamızda saptanan IM'lerin tümünün tipi inkomplet iM olup, hiçbir hastada kansere dönüşme riski daha yüksek olan komplet IM saptanmamıştır.

Çalışmanın retrospektif yapısı nedeniyle bazı hastaların patolojik raporları veya diğer verileri eksik olduğundan, katılımc sayımızın azalması çalışmanın kısıtlılıklarından biridir. Ayrıca birden fazla biyopsinin alındığı prospektif çalışmalarda IM insidansının daha yüksek olacağını düşünmekteyiz. Bu nedenle bu konuda yapılacak daha kapsamlı prospektif çalışmalara intiyaç vardır.

Bu tek merkez verileri ile diğer bölgelere kıyasla muhtemelen yaşam tarzı ve sosyoekonomik koşullardan kaynaklanan daha yüksek IM sıkığı yeme alışkanlıkları ve yaşam tarzı değişiklikleri ile büyük ölçüde azaltılabilir. Insidansı yüksek olduğu bilinen mide kanserinin bir öncüsü olarak kabul edilen İM'nin yeterince erken bir zamanda saptanması, tedavisi ve takibi oldukça önem taşımaktadır.

"Tüm yazarlar herhangi bir çıkar çatışması olmadı̆̆ını kabul ederler." 


\section{KAYNAKLAR}

1. Slack JM, Tosh D. Transdifferentiation and metaplasia-switching cell types. Curr Opin Genet Dev 2001;11:581-6.

2. Slack JMW. Metaplasia and transdifferentiation: from pure biology to the clinic. Nat Rev Mol Cell Biol 2007;8:369-78.

3. Mohan H, Punia RPS, Dhawan SB, Ahal S, Sekhon MS. Morphological spectrum of gallstone disease in 1100 cholecystectomoies in north india. Ind J Surg 2005;67:140-2.

4. Sharma P, Falk GW, Weston AP, et al. Dysplasia and cancer in a large multicenter cohort of patients with Barrett's esophagus. Clin Gastroenterol Hepatol 2006;4:566-72.

5. Giroux V, Rustgi AK. Metaplasia: tissue injury adaptation and a precursor to the dysplasia-cancer sequence. Nat Rev Cancer 2017;17:594-604.

6. Kumar V, Abbas AK, Fausto N, \& Mitchell RN. Robbins Basic Pathology (8th ed.). Saunders Elsevier. 2007;pp.716-720, ISBN 978-14160-2973-1.

7. Chuvin N, Vincent DF, Pommier, RM et al. Acinar-to-ductal metaplasia induced by transforming growth factor beta facilitates KRASG12D-driven pancreatic tumorigenesis. Cell Mol Gastroenterol Hepatol 2017;4:263-82.

8. Choi AY, Strate LL, Fix MC, et al. Association of gastric intestinal metaplasia and East Asian ethnicity with the risk of gastric adenocarcinoma in a U.S. population. Gastrointest Endosc 2018;87:10238

9. Karimi P, Islami F, Anandasabapathy S, Freedman ND, Kamangar F. Gastric cancer: descriptive epidemiology, risk factors, screening, and prevention. Cancer Epidemiol Biomarkers Prev 2014;23:70013.

10. Correa P, Piazuelo MB, Wilson KT. Pathology of gastric intestinal metaplasia: clinical implications. Am J Gastroenterol 2010;105:4938.

11. Lee KJ, Inoue M, Otani T, et al. Gastric cancer screening and subsequent risk of gastric cancer: a large-scale population-based cohort study, with a 13-year follow-up in Japan. Int J Cancer 2006;118:2315-21.

12. Hvid-Jensen F, Pedersen L, Drewes AM, Sorensen HT, Funch-Jensen $P$. Incidence of adenocarcinoma among patients with Barrett's esophagus. N Engl J Med 2011;365:1375-83.

13. Zullo A, Hassan C, Romiti A, et al. Follow-up of intestinal metaplasia in the stomach: When, how and why. World J Gastrointest Oncol 2012:4:30-6.

14. Tava F, Luinetti $O$, Ghigna MR, et al. Type or extension of intestinal metaplasia and immature/atypical "indefinite-for-dysplasia" lesions as predictors of gastric neoplasia. Hum Pathol 2006;37:1489-97.

15. Zullo A, Hassan C. How harmful is the presence of intestinal metaplasia in the stomach? Gastroenterology 2009;136:1461-2.

16. Sonnenberg A, Lash RH, Genta RM. A national study of Helicobactor pylori infection in gastric biopsy specimens. Gastroenterology 2010;139:1894-e12.

17. Bor S, Vardar R, Ormeci N, et al. Prevalence patterns of gastric cancers in Turkey: model of a developing country with high occurrence of Helicobacter pylori [published correction appears in J Gastroenterol Hepatol 2008;23:1309]. J Gastroenterol Hepatol 2007:22:2242-5
18. Mete R, Oran M, Günes $H$, ve ark. Tekirdağ bölgesinde Helicobacter pylori prevalansı ve patolojik parametrelerin çok yönlü analizi; literatür ile güncelleme. Genel Tıp Derg 2014;24:1-6.

19. Ozdil K, Sahin A, Kahraman R, et al. Current prevalence of intestinal metaplasia and Helicobacter pylori infection in dyspeptic adult patients from Turkey. Hepatogastroenterology 2010;57:1563-6.

20. Konakcl, Gülte M, İbanoğlu MS, ve ark. Kronik aktif gastritli olgularda Helicobacter pylori sıklığı. Uludağ Üniv Tıp Fakül Derg 2010;36:7-10

21. Adım ŞB, Filiz G, Gürel S, Yerci Ö, Özgür T. Kronik gastrit olgularında intestinal metaplazi sıklığı ve intestinal metaplazi ile Helicobacter pylori ilişkisi. Uludağ Üniv Tıp Fakül Derg 2008;34:1-4.

22. Akpolat N. Helicobacter pylorinin midede oluşturduğu morfolojik değişiklikler. Uzmanlık tezi. Van: Van Üniversitesi; 1998.

23. Taşkın V, Gürer I, Sarı R, et al. The prevalence of lymphoid follicles and intestinal metaplasia in Helicobacter pylori associated cli nically significant gastroduodenal diseases. Turk J Gastroenterol 1999;10:197-201

24. Olmez S, Aslan M, Erten R, Sayar S, Bayram I. The prevalence of gastric intestinal metaplasia and distribution of Helicobacter pylori infection, Atrophy, dysplasia, and cancer in its subtypes. Gastroenterol Res Pract 2015;2015:434039.

25. Eriksson NK, Kärkkäinen PA, Färkkilä MA, Arkkila PE. Prevalence and distribution of gastric intestinal metaplasia and its subtypes. Dig Liver Dis 2008;40:355-60.

26. Campbell DI, Warren BF, Thomas JE, Figura N, Telford JL, Sullivan PB. The African enigma: low prevalence of gastric atrophy, high prevalence of chronic inflammation in West African adults and children. Helicobacter 2001;6:263-7.

27. Cassaro M, Rugge M, Gutierrez $O$, et al. Topographic patterns of intestinal metaplasia and gastric cancer. Am J Gastroenterol 2000;95:1431-8.

28. Malekzadeh R, Sotoudeh M, Derakhshan MH, et al. Prevalence of gastric precancerous lesions in Ardabil, a high incidence province for gastric adenocarcinoma in the northwest of Iran. J Clin Pathol 2004; 57:37-42

29. Xia HH, Kalantar JS, Talley NJ, et al. Antral-type mucosa in the gastric incisura, body, and fundus (antralization): a link between Helicobacter pylori infection and intestinal metaplasia?. Am J Gastroenterol 2000;95:114-21.

30. Guner SI, Tuncer M. Incidence of atrophic gastritis and intestinal metaplasia in patients with Helicobacter pylori positive duodenal ulcer and non-ulcer dyspepsia. Medical Journal of Bakırkoy 2019;15:272-9

31. Ibis M, Arhan M, Odemis B, et al. Endoskooik olarak tanımlanan gastrit ile histolojik bulgular arasındaki ilişki. Akademik Gastroenteroloji Dergisi 2009;8:12-7.

32. Kneller RW, You WC, Chang YS, et al. Cigarette smoking and other ris-k factors for progression of precancerous stomach lesions. J Nat Cancer Inst 1992:84:1261-6. 